\title{
Human Mastadenovirus Infections and Meteorological Factors in Cheonan, Korea
}

\author{
Eun Ju Oh ${ }^{1 \dagger}$, Joowon Park ${ }^{2 \dagger}$, and Jae Kyung Kim ${ }^{3 *}$ \\ ${ }^{1}$ Department of Medical Laser, Dankook University Graduate School of Medicine, Cheonan 31116, Republic of Korea \\ ${ }^{2}$ Department of Laboratory Medicine, Dankook University College of Medicine, Cheonan 31116, Republic of Korea \\ ${ }^{3}$ Department of Biomedical Laboratory Science, Dankook University College of Health Sciences, Cheonan 31116, Republic of Korea
}

Received: October 23, 2020 / Revised: January 14, 2021 / Accepted: January 29, 2021

\begin{abstract}
The study of the impact of weather on viral respiratory infections enables the assignment of causality to disease outbreaks caused by climatic factors. A better understanding of the seasonal distribution of viruses may facilitate the development of potential treatment approaches and effective preventive strategies for respiratory viral infections. We analyzed the incidence of human mastadenovirus infection using real-time reverse transcription polymerase chain reaction in 9,010 test samples obtained from Cheonan, South Korea, and simultaneously collected the weather data from January 1, 2012, to December 31, 2018. We used the data collected on the infection frequency to detect seasonal patterns of human mastadenovirus prevalence, which were directly compared with local weather data obtained over the same period. Descriptive statistical analysis, frequency analysis, $t$-test, and binomial logistic regression analysis were performed to examine the relationship between weather, particulate matter, and human mastadenovirus infections. Patients under 10 years of age showed the highest mastadenovirus infection rates (89.78\%) at an average monthly temperature of $18.2^{\circ} \mathrm{C}$. Moreover, we observed a negative correlation between human mastadenovirus infection and temperature, wind chill, and air pressure. The obtained results indicate that climatic factors affect the rate of human mastadenovirus infection. Therefore, it may be possible to predict the instance when preventive strategies would yield the most effective results.
\end{abstract}

Keywords: Climate, mastadenovirus, respiratory viruses, infection, particulate matter, weather

\section{Introduction}

Respiratory tract infections are among the most common human ailments [1]. Lower respiratory tract infections are a continuing public health issue, with a mortality rate of $0.036 \%$, resulting in more than two million deaths per year worldwide [2]. Infections caused by generic viral pathogens, such as the human mastadenovirus (HAdVs), respiratory syncytial virus, influenza $A$ and $B$ viruses, and parainfluenza virus, are leading

\section{*Corresponding author}

Tel: +82-41-550-1451, Fax: +82-41-559-7934

E-mail: nerowolf2@dankook.ac.kr

${ }^{\dagger}$ These authors contributed equally to this work. causes of lower respiratory tract infections in children $[3,4]$.

HAdVs is a non-enveloped DNA virus that belongs to the family Adenoviridae, genus Mastadenovirus, and species Human mastadenovirus; it is classified into seven types, denoted by the letters A to G, based on its DNA homology [6-8]. Currently, more than 80 serotypes have been identified by applying biochemical and biological standards [9]. HAdVs infection in immunocompromised patients, or those infected with a specific serotype, manifests in severe illness that may result in death [9, 10]. HAdVs may cause severe, and often fatal, pneumonia or bronchiolitis [5]. HAdVs account for approximately $10 \%$ of the lower respiratory tract infections in children [11]. HAdVs can be transmitted 
through the respiratory system, with the alveolar and oral paths being the main propagation routes in children [9].

There are currently no commercial vaccines against respiratory viruses (RVs), except influenza $\mathrm{A}$ and $\mathrm{B}$. Thus, preventing and effectively controlling viral infections can present themselves as a heinous task [12]. Therefore, investigations on the viral etiology of respiratory infections that occur at various ages and climatic/ seasonal periods are crucial for successfully implementing prevention, control, and treatment strategies [13].

Several theories have been proposed to explain influenza's seasonal patterns; however, few studies have examined the relationship between climate and HAdVs incidence [14]. In the present study, the effects of weather on the seasonal dynamics of HAdVs under warm climatic conditions were investigated. Understanding the effects of climate on HAdVs infections may help minimize the requirement for immunization and enable timely prevention of infections with the development of future vaccines. Additionally, the current study provides basic epidemiological data for establishing HAdVs infection and prevention measures in the community.

This would be with a specific focus on the impact of environmental/weather-related variables on the rate of spread of HAdVs infection.

\section{Materials and Methods}

\section{Sample collection}

All respiratory samples used in the study were obtained as nasal/throat swabs or non-pharyngeal aspirates from patients with suspected respiratory diseases from January 1, 2012, to December 31, 2018. These samples were sent to the Dankook University School Hospital's medical laboratory in Cheonan City, Republic of Korea, for real-time reverse transcriptasepolymerase chain reaction (RT-PCR) analysis. Each patient provided a single sample; duplicate tests performed on the same date were not included in our analysis. Outpatient samples were also excluded from the data analysis. Samples were either tested immediately after being obtained or refrigerated at $4^{\circ} \mathrm{C}$ (if not immediately available for testing) and tested within $24 \mathrm{~h}$.

\section{Ethical approval}

The present study was approved by the IRB Committee of the Dankook University (No. 2019-12-007) and was conducted in accordance with the Declaration of Helsinki. Due to the retrospective nature of the study, consent forms were not required.

\section{Real-time RT-PCR}

Respiratory samples were processed with the QIAamp MinElute Virus Spin Kit (Qiagen, Germany) to extract nucleic acids [26]. Extracted nucleic acids was subsequently amplified and tested for RVs using AdvanSure RV real-time RT-PCR (LG Life Science, Korea) according to the manufacturer's instructions. AdvanSure RV real-time RT-PCR (LG Life Science) is known to detect HAdVs types 1, 2, 3, 4, 5, 8, 11, 12, 18, 23, and 35 [27].

\section{Sources of climate data}

The National Institute of Environmental Sciences is managed by the Ministry of Environment in South Korea, overseeing domestic research and educational initiatives in relation to the environment. The automated synoptic observing system (ASOS) is a manned weather measurement system by which the Korea Meteorological Agency obtains information on changes in weather factors. Weather data for the Cheonan region for the period January 1, 2012 to December 31, 2018, were obtained by the Korea Meteorological Administration; particulate matter data were obtained from the National Institute of Environmental Research. Daily weather information data were obtained from ASOS. Variables used in the study included the date, month, and year during which the samples were obtained, age and sex of the patients, and climatic variables.

\section{Climatic variables}

Cheonan, Chungcheongnam-do, Korea, has a typical temperate climate; its coordinates are $36.47^{\circ} \mathrm{N}$, $127.13^{\circ} \mathrm{E}$, covering an area of $636.3 \mathrm{~km}^{2}$. Daily ASOS and particulate matter concentration data were collected. Climate data including date and time of precipitation $(\mathrm{mm})$, air temperature $\left({ }^{\circ} \mathrm{C}\right)$, wind chill temperature $\left({ }^{\circ} \mathrm{C}\right)$, daily temperature range $\left({ }^{\circ} \mathrm{C}\right)$, monthly average temperature $\left({ }^{\circ} \mathrm{C}\right)$, relative humidity $(\%)$, atmospheric pressure $(\mathrm{hPa})$, and particulate matter concen- 
tration $\left(\mu \mathrm{g} / \mathrm{m}^{3}\right)$ were used to analyze climate variables. Rainfall data were not analyzed. Wind chill temperatures were assessed using the formula:

$$
13.12+0.6215 \times \mathrm{T}-11.37 \mathrm{~V} 0.16+0.3965 \mathrm{~V} 0.16 \times \mathrm{T}
$$

where $\mathrm{T}$ denotes the air temperature $\left({ }^{\circ} \mathrm{C}\right)$ and $\mathrm{V}$ denotes the wind speed $(\mathrm{km} / \mathrm{h})$ measured $10 \mathrm{~m}$ above ground.

\section{Statistical analysis}

SAS version 9.4 (SAS Institute, Inc., USA) was used to perform descriptive statistical analysis, frequency analysis, Student's $t$-test, and binomial logistic regression analysis to investigate the correlation of meteorological and particulate matter concentrations with the human mastadenovirus detection rate. Continuous data are presented as the mean, and categorical data are presented as frequencies and percentages, where appropriate. For all the analyses, a 2 -tailed $p$-value less than 0.05 was considered statistically significant.

\section{Results}

In 2019, there were approximately 650,000 residents in Cheonan, Korea. In the present study, samples obtained from 9,010 patients with respiratory infection symptoms, who visited the Dankook University Hospital between January 2012 and December 2018, were evaluated. A total of 890 patients tested positive for HAdVs, accounting for $9.88 \%(890 / 9,010)$ of the total number of individuals with respiratory disease symptoms who visited the hospital (Table 1). Of these patients, $72.81 \%$ (648/890) were aged 1-9 years (Table 1). A higher detection rate of HAdVs was observed in the 1-9 years age group $(72.81 \%, 648 / 890)$ than in the $<1$ year age group $(18.90 \%, 151 / 890)$ (Table 1$)$. In addition, a
Table 1. Demographics of patients enrolled in this study.

\begin{tabular}{ccc}
\hline \multirow{2}{*}{ Age } & \multicolumn{2}{c}{ HAdVs } \\
\cline { 2 - 3 } & $\mathrm{N}$ & $\%$ \\
\hline $1 \sim 9$ & 151 & 16.97 \\
$10 \sim 19$ & 648 & 72.81 \\
$20 \sim 29$ & 27 & 3.03 \\
$30 \sim 39$ & 5 & 0.56 \\
$40 \sim 49$ & 8 & 0.9 \\
$50 \sim 59$ & 9 & 1.01 \\
$60 \sim$ & 10 & 1.12 \\
\hline Total & 32 & 3.6 \\
\hline Sex & 890 & 100 \\
\hline Male & $\mathrm{N}$ & $\%$ \\
\hline Female & 526 & 59.1 \\
\hline Total & 364 & 40.9 \\
\hline Infection amounts & 890 & 100 \\
\hline 1 (only HAdVs) & $\mathrm{N}$ & $\%$ \\
\hline 2 & 432 & 48.54 \\
3 & 375 & 42.13 \\
4 & 79 & 8.88 \\
\hline Total & 4 & 0.45 \\
\hline & 890 & 100 \\
\hline
\end{tabular}

higher HAdVs detection rate was observed in the male group $(59.10 \%, 526 / 890)$ than in the female group (40.90\%, 364/890) (Table 1). Of the 890 patients who tested positive for HAdVs, 432 were infected with HAdVs only, whereas the other 458 patients were simultaneously infected with other respiratory viruses.

Patients were observed to have been infected by HAdVs throughout the year. The highest HAdVs incidence rate was noted to be in March 2013, with the second highest rate being recorded in December 2015 (Fig. 1). The Student's $t$-test demonstrated that the

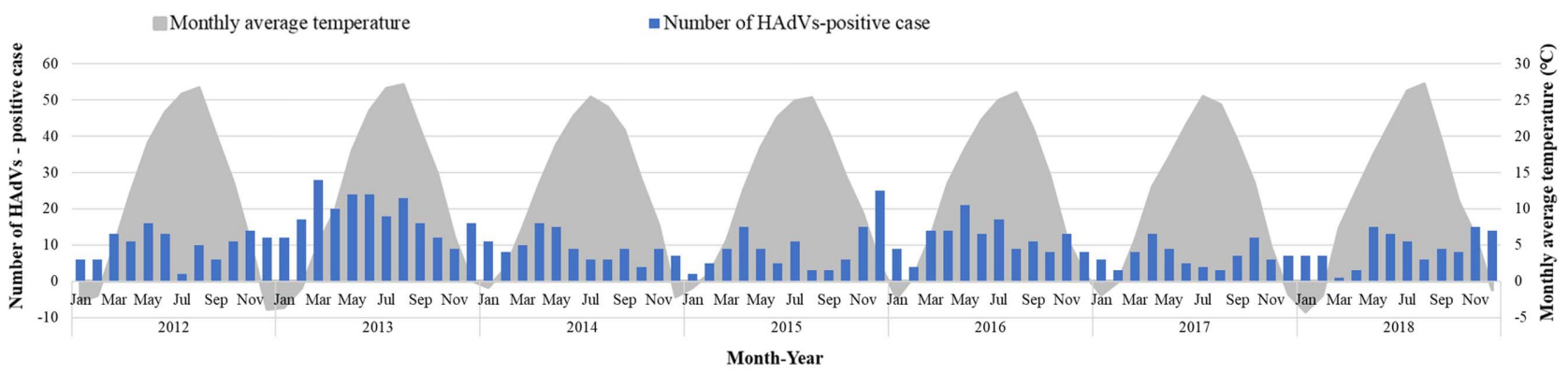

Fig. 1. HAdVs-positive cases aggregated by monthly average temperature (2012-2018). 
Table 2. Daily mean meteorological factors and particulate matter and correlation with HAdVs infection.

\begin{tabular}{|c|c|c|c|c|c|c|c|}
\hline \multirow{2}{*}{ Virus } & \multirow{2}{*}{$\begin{array}{l}\text { Meteorological factor and } \\
\text { Particulate Matter }\end{array}$} & \multirow{2}{*}{$\begin{array}{l}\text { HAdVs- } \\
\text { positive }\end{array}$} & \multirow{2}{*}{$\begin{array}{l}\text { HAdVs- } \\
\text { negative }\end{array}$} & \multirow{2}{*}{$\begin{array}{l}\text { Difference in } \\
\text { means }\end{array}$} & \multicolumn{2}{|c|}{$95 \% \mathrm{Cl}$} & \multirow{2}{*}{$p$-value } \\
\hline & & & & & Lower & Upper & \\
\hline \multirow{5}{*}{ HAdVs } & Temperature $\left({ }^{\circ} \mathrm{C}\right)$ & 13.10 & 11.38 & 1.73 & 0.980 & 2.474 & $<0.0001$ \\
\hline & Wind chill Temperature $\left({ }^{\circ} \mathrm{C}\right)$ & 12.61 & 10.79 & 1.82 & 1.032 & 2.616 & $<0.0001$ \\
\hline & Relative Humidity (\%) & 68.01 & 67.35 & 0.67 & -0.30 & 1.63 & 0.176 \\
\hline & Atmospheric Pressure (hPa) & 1004.7 & 1008.1 & -3.4 & -4.455 & -2.308 & $<0.0001$ \\
\hline & Particulate Matter $\left(\mu \mathrm{g} / \mathrm{m}^{3}\right)$ & 52.14 & 50.49 & 1.65 & -0.489 & 3.789 & 0.131 \\
\hline \multirow{2}{*}{ Virus } & \multirow{2}{*}{$\begin{array}{l}\text { Meteorological factor and } \\
\text { Particulate Matter }\end{array}$} & \multirow{2}{*}{$\begin{array}{l}\text { HAdVs- } \\
\text { positive }\end{array}$} & \multirow{2}{*}{$\begin{array}{l}\text { HAdVs- } \\
\text { negative }\end{array}$} & \multirow{2}{*}{$\begin{array}{l}\text { Difference in } \\
\text { means }\end{array}$} & \multicolumn{2}{|c|}{$95 \% \mathrm{Cl}$} & \multirow{2}{*}{$p$-value } \\
\hline & & & & & Lower & Upper & \\
\hline \multirow{5}{*}{ HAdVs } & Temperature $\left({ }^{\circ} \mathrm{C}\right)$ & 13.10 & 11.38 & 1.73 & 0.980 & 2.474 & $<0.0001$ \\
\hline & Wind chill Temperature $\left({ }^{\circ} \mathrm{C}\right)$ & 12.61 & 10.79 & 1.82 & 1.032 & 2.616 & $<0.0001$ \\
\hline & Relative Humidity (\%) & 68.01 & 67.35 & 0.67 & -0.30 & 1.63 & 0.176 \\
\hline & Atmospheric Pressure (hPa) & 1004.7 & 1008.1 & -3.4 & -4.455 & -2.308 & $<0.0001$ \\
\hline & Particulate Matter $\left(\mu \mathrm{g} / \mathrm{m}^{3}\right)$ & 52.14 & 50.49 & 1.65 & -0.489 & 3.789 & 0.131 \\
\hline
\end{tabular}

Significant $p$-values are shown in bold.

Confidence interval $(\mathrm{Cl})$ is a type of estimate computed from the statistics of the observed data.

mean values for temperature, wind chill temperature, and atmospheric pressure were significantly different from the corresponding readings on the days when the HAdVs infection was detected as opposed to when an infection was not (Table 2). In contrast, no significant differences were observed in the relative humidity or particulate matter relative to the infection detection rate. Of the significant differences, the daily temperature range presented the smallest difference in mean while the atmospheric pressure showed the largest (mean difference $0.10, p=0.498 ;-3.2, p<0.0001$, respectively), based on the HAdVs detection rate.

The assessment through binary logistic regression analysis demonstrated that temperature, wind chill temperature, and atmospheric pressure were signifi- cantly associated with HAdVs infection. The odds of developing mastadenovirus infection were lower per unit increase in temperature and wind chill, and greater per unit increase in atmospheric pressure (Table 3).

\section{Discussion}

Respiratory infections due to HAdVs pose a formidable challenge to global health. The present study demonstrated that, in temperate zones, the likelihood of the incidence of an HAdVs infection increases at a temperature of $18.2^{\circ} \mathrm{C}$, particularly in April through June, November, and December. During the study period, May 2016 had the average temperature of $18.2^{\circ} \mathrm{C}$. Wind chill temperature and atmospheric pressure presented signif-

Table 3. Significant correlation between meteorological factors and particulate matter and HAdVs.

\begin{tabular}{|c|c|c|c|c|c|}
\hline \multirow{2}{*}{ Virus } & \multirow{2}{*}{$\begin{array}{l}\text { Meteorological factor and } \\
\text { Particulate matter }\end{array}$} & \multirow{2}{*}{ P-value } & \multirow{2}{*}{ Odds ratio } & \multicolumn{2}{|c|}{$95 \% \mathrm{Cl}$ for odds ratio } \\
\hline & & & & Lower & Upper \\
\hline \multirow{5}{*}{ HAdVs } & Temperature $\left({ }^{\circ} \mathrm{C}\right)$ & $<0.0001$ & 0.772 & 0.679 & 0.878 \\
\hline & Wind-chill temperature $\left({ }^{\circ} \mathrm{C}\right)$ & $<0.001$ & 0.803 & 0.705 & 0.913 \\
\hline & Relative humidity (\%) & 0.072 & 0.889 & 0.781 & 1.011 \\
\hline & Atmospheric pressure $(\mathrm{hPa})$ & $<0.0001$ & 1.476 & 1.297 & 1.680 \\
\hline & Particulate matter $\left(\mu \mathrm{g} / \mathrm{m}^{3}\right)$ & 0.217 & 0.921 & 0.809 & 1.049 \\
\hline
\end{tabular}

Significant $p$-values are shown in bold. 
icant effects on HAdVs infection rates. Relatively few studies have examined the relationship between viral infections and wind chill. Herein, the effects of temperature, wind chill, and atmospheric pressure were shown to negatively impact HAdVs infection.

Although the seasonal nature of certain viruses in temperate climates is well known, the relationship between different climatic variables and virus infection remains unclear [15]. Particulate matter is divided into two different categories based on particle size: PM10, fine dust with a diameter of less than $10 \mu \mathrm{m}$; and PM2.5, fine dust with a diameter of less than $2.5 \mu \mathrm{m}$ [16]. Several studies have investigated the relationship between particle sizes of PM10 and airborne respiratory viruses; however, the findings were inconclusive because of technical limitations [17-22]. The size and composition of fine dust particles are quite complex and diverse [23]. Our observations confirmed no correlation between increased rates of HAdVs infection and the presence of particulate matter.

The objective of the present study was to relate medical and weather data on specific respiratory virus infections in the same region over 7 years to produce a basis for future research. The development of HAdVs infections was lower per unit increase in temperature and wind chill; conversely, infections were greater per unit increase in atmospheric pressure.

There were certain limitations to the present study. First, a 7-year investigation in only one city is comparatively short; therefore, the results may be limited and biased. Some of the samples tested may have been obtained from patients who do not reside in the studied area because the sample data were processed anonymously, and the residence of the patient was not specified. However, all samples obtained over the test period were analyzed and considered representative of the population. Second, biological standards have been identified for more than 80 serotypes of HAdVs [20]. However, in the present study, the HAdVs serotype was not analyzed separately. Therefore, further studies are needed to identify HAdVs subtypes. Additionally, the asymptomatic prevalence and pathogenicity of HAdVs should be evaluated [24]. Finally, multiple factors may affect viral infectious diseases [25]; in addition to the climate data analysis, several other climatic factors may impact them. Our results may, therefore, be insufficient to arrive at a final interpretation. Further research is warranted on the correlation between HAdVs and additional climatic factors such as ozone concentrations and fine particulate matter.

Despite these limitations, the obtained findings improve our understanding of how seasons modulate virus infection distributions, allowing public health officials to develop effective prevention strategies. A more comprehensive, systematic medical treatment strategy for respiratory infection-sensitive people, which is directly climate-related, may be implemented. Linking medical data with additional individual information will provide a specific disease prevalence rate and patientspecific patterns of behavior, leading to improved overall healthcare standards in the region.

\section{Acknowledgments}

The present study was supported by the Basic Science Research Program through the National Research Foundation of Korea (NRF) funded by the Ministry of Education (grant No. R202000217). This study was approved by the Institutional Review Board Committee of Dankook University (No. 2019-12-007). This study was conducted in accordance with the Declaration of Helsinki.

\section{Conflict of Interest}

The authors have no financial conflicts of interest to declare.

\section{References}

1. Liu Y, Guo Y, Wang C, Li W, Lu J, Shen S, et al. 2015. Association between temperature change and outpatient visits for respiratory tract infections among children in Guangzhou, China. Int. J. Environ. Res. Public Health 12: 439-454.

2. Wang Y, Dong T, Qi G, Qu L, Liang W, Qi B, et al. 2018. Prevalence of common respiratory viral infections and identification of adenovirus in hospitalized adults in Harbin, China 2014 to 2017. Front. Microbiol. 9: 2919.

3. Pavia AT. 2011. Viral infections of the lower respiratory tract: old viruses, new viruses, and the role of diagnosis. Clin. Infect. Dis. 52(Suppl. 4): S284-S289.

4. Choi EH, Lee HJ, Kim SJ, Eun BW, Kim NH, Lee JA, et al. 2006. The association of newly identified respiratory viruses with lower respiratory tract infections in Korean children, 2000-2005. Clin. Infect. Dis. 43: 585-592.

5. Kim Y-J, Hong J-Y, Lee H-J, Shin S-H, Kim Y-K, Inada T, et al. 2003. Genome type analysis of adenovirus types 3 and 7 isolated during successive outbreaks of lower respiratory tract infections in children. J. Clin. Microbiol. 41: 4594-4599. 
6. De Jong JC, Wermenbol AG, Verweij-Uijterwaal MW, Slaterus KW, Wertheim-Van Dillen P, Van Doornum, GJ, et al. 1999. Adenoviruses from human immunodeficiency virus-infected individuals, including two strains that represent new candidate serotypes Ad50 and Ad51 of species B1 and D, respectively. J. Clin. Microbiol. 37: 3940-3945.

7. Walsh MP, Chintakuntlawar A, Robinson CM, Madisch I, Harrach B, Hudson NR, et al. 2009. Evidence of molecular evolution driven by recombination events influencing tropism in a novel human adenovirus that causes epidemic keratoconjunctivitis. PLoS One 4: e5635.

8. Walsh MP, Seto J, Jones MS, Chodosh J, Xu W, Seto D. 2010. Computational analysis identifies human adenovirus type 55 as a reemergent acute respiratory disease pathogen. J. Clin. Microbiol. 48: 991-993.

9. Lee H-K, Lee M-J, Mun S-K, Kim W-H, Cho H-G, Yoon M-H, et al. 2012. Serotype distribution of human respiratory adenovirus isolated in Gyeonggi province. Korean J. Microbiol. 48: 175-179.

10. Wadell G. 1984. Molecular epidemiology of human adenoviruses, pp. 191-220. In: Doerfler W. (eds.), Curr. Top. Microbiol. Immunol. vol. 110. Springer, Berlin, Heidelberg.

11. Moura PO, Roberto AF, Hein N, Baldacci E, Vieira SE, Ejzenberg B, et al. 2007. Molecular epidemiology of human adenovirus isolated from children hospitalized with acute respiratory infection in Sao Paulo, Brazil. J. Med. Virol. 79: 174-181.

12. Lambkin-Williams R, Noulin N, Mann A, Catchpole A, Gilbert AS. 2018. The human viral challenge model: accelerating the evaluation of respiratory antivirals, vaccines and novel diagnostics. Respir. Res. 19: 123.

13. He $Y$, Lin G-Y, Wang Q, Cai X-Y, Zhang Y-H, Lin C-X, et al. 2014. A 3-year prospective study of the epidemiology of acute respiratory viral infections in hospitalized children in Shenzhen, China. Influenza Other Respir. Viruses 8: 443-451.

14. Chen G, Zhang W, Li S, Zhang Y, Williams G, Huxley R, et al. 2017. The impact of ambient fine particles on influenza transmission and the modification effects of temperature in China: a multi-city study. Environ. Int. 98: 82-88.

15. Tamerius J, Nelson MI, Zhou SZ, Viboud C, Miller MA, Alonso WJ. 2011. Global influenza seasonality: reconciling patterns across temperate and tropical regions. Environ. Health Perspect. 119: 439-445.

16. Ciencewicki J, Jaspers I. 2007. Air pollution and respiratory viral infection. Inhal. Toxicol. 19: 1135-1146.
17. Imai C, Hashizume M. 2015. A systematic review of methodology: time series regression analysis for environmental factors and infectious diseases. Trop. Med. Health 43: 1-9.

18. Cao C, Jiang W, Wang B, Fang J, Lang J, Tian G, et al. 2014. Inhalable microorganisms in Beijing's PM2.5 and PM10 pollutants during a severe smog event. Environ. Sci. Technol. 48: 1499-1507.

19. Vandini S, Corvaglia L, Alessandroni R, Aquilano G, Marsico C, Spinelli $M$, et al. 2013. Respiratory syncytial virus infection in infants and correlation with meteorological factors and air pollutants. Ital. J. Pediatr. 39: 1.

20. Liu Y, Xie S, Yu Q, Huo X, Ming X, Wang J, et al. 2017. Short-term effects of ambient air pollution on pediatric outpatient visits for respiratory diseases in Yichang city, China. Environ. Pollut. 227: 116-124.

21. Zhu L, Ge X, Chen Y, Zeng X, Pan W, Zhang X, et al. 2017. Shortterm effects of ambient air pollution and childhood lower respiratory diseases. Sci. Rep. 7: 4414.

22. Shin DC. 2007. Health effects of ambient particulate matter. J. Korean Med. Assoc. 50: 175-182.

23. Oh JS, Park SH, Kwak MK, Pyo CH, Park KH, Kim HB, et al. 2017. Ambient particulate matter and emergency department visit for chronic obstructive pulmonary disease. J. Korean Soc. Emerg. Med. 28: 32-39.

24. Altamimi A, Ahmed AE. 2020. Climate factors and incidence of Middle East respiratory syndrome coronavirus. J. Infect. Public Health 13: 704-708.

25. Liu W-K, Chen D-H, Tan W-P, Qiu S-Y, Xu D, Zhang L, et al. 2019. Paramyxoviruses respiratory syncytial virus, parainfluenza virus, and human metapneumovirus infection in pediatric hospitalized patients and climate correlation in a subtropical region of southern China: a 7-year survey. Eur. J. Clin. Microbiol. Infect. Dis. 38: $2355-2364$.

26. Templeton KE, Scheltinga SA, Beersma MFC, Kroes ACM, Claas ECJ. 2004. Rapid and sensitive method using multiplex real-time PCR for diagnosis of infections by influenza $A$ and influenza $B$ viruses, respiratory syncytial virus, and Parainfluenza Viruses 1, 2, 3, and 4. J. Clin Microbiol. 42940: 1564-1569.

27. Ko DH, Kim HS, Hyun J, Kim HS, Kim JS, Park KU. 2017. Comparison of the Luminex XTAG respiratory viral panel Fast v2 assay with Anyplex II RV16 detection kit and AdvanSure RV real-time RT-PCR assay for the detection of respiratory viruses. Ann. Lab Med. 37: 408-414. 